\title{
Disfunção craniocervicomandibular e alterações vestibulococleares: revisão de literatura
}

\author{
Cranio-cervico-mandibular disorders and vestibulocochlear alterations: literature review \\ Trastornos cráneo-cervico-mandibulares y alteraciones vestibulococleares: revisión de la literatura \\ Géssica Vasconcelos GODINHO \\ Lioney Nobre CABRAL ${ }^{2}$
}

${ }^{1}$ Graduada em Odontologia pela Universidade do Estado do Amazonas, UEA, 69065-001, Manaus - AM, Brasil

${ }^{2}$ Doutor em Biotecnologia pela Universidade Federal do Amazonas, UFAM, Professor adjunto do curso de Odontologia da Universidade do Estado do Amazonas, UEA, 69065-001, Manaus - AM, Brasil

\section{Resumo}

As disfunções temporomandibulares referem-se a um conjunto de condições que afetam os músculos da mastigação e/ou a articulação temporomandibular. Quando esta condição abrange também problemas clínicos na região cervical, utiliza-se o termo disfunção craniocervicomandibular. Além de comprometer funções próprias do sistema estomatognático, as alterações nas estruturas da ATM podem trazer sintomatologia auditiva associada devido à grande proximidade anatômica e funcional entre os componentes da orelha e ATM. O objetivo deste trabalho foi revisar estudos da literatura sobre etiologia, manifestações clínicas, fisiopatogenia, diagnóstico e tratamento das disfunções craniocervicomandibulares associadas a sintomatologia vestibulococlear, a fim auxiliar acadêmicos e profissionais no estudo desta condição dolorosa crônica.

Descritores: Articulação Temporomandibular; Cervicalgia; Pontos-Gatilho; Transtornos Craniomandibulares; Síndromes da Dor Miofascial.

\section{Abstract}

Temporomandibular disorders refer to a set of conditions that affect the chewing muscles and / or the temporomandibular joint. When this condition also includes clinical problems in the cervical region, the term craniocervicomandibular dysfunction is used. In addition to impairing proper functions of the stomatognathic system, changes in TMJ structures can bring associated auditory symptomatology due to the great anatomical and functional proximity between the ear and TMJ components. The objective of this study was to review studies on the etiology, clinical manifestations, pathophysiology, diagnosis and treatment of craniocervicomandibular disorders associated with vestibulocochlear symptoms, in order to assist academic and professionals in the study of this chronic painful condition.

Descriptors: Temporomandibular Joint; Neck Pain; Trigger Points; Craniomandibular Disorders; Myofascial Pain Syndromes.

\section{Resumen}

Las disfunciones temporomandibulares se refieren a un conjunto de condiciones que afectan los músculos de la masticación y / o la articulación temporomandibular. Cuando esta condición abarca también problemas clínicos en la región cervical, se utiliza el término disfunción craniocervicomandibular. Además de comprometer funciones propias del sistema estomatognático, los cambios en las estructuras de la ATM pueden traer sintomatología auditiva asociada debido a la gran proximidad anatómica y funcional entre los componentes de la oreja y ATM. El objetivo de este trabajo fue revisar estudios de la literatura sobre etiología, manifestaciones clínicas, fisiopatogenia, diagnóstico y tratamiento de las disfunciones craniocervicomandibulares asociadas a sintomatología vestibulococlear, a fin de auxiliar a académicos y profesionales en el estudio de esta condición dolorosa crónica.

Descriptores: Articulación Temporomandibular; Dolor de Cuello; Puntos Disparadores; Trastornos Craneomandibulares; Síndromes del Dolor Miofascial.

\section{INTRODUÇÃO}

O conjunto de distúrbios que envolvem a articulação temporomandibular (ATM), os músculos mastigatórios e estruturas associadas é definido pela Associação Americana de Dor Orofacial como disfunção temporomandibular (DTM), classificada em DTM muscular e DTM articular ${ }^{1}$. Quando essas alterações se associam a problemas clínicos na região cervical, denomina-se disfunção craniocervicomandibular (DCCM $)^{2}$.

Multifatores são apontados como causas, sendo estes os distúrbios da oclusão e traumas que sobrecarregam a articulação temporomandibular, hábitos deletérios, próteses mal adaptadas ou restaurações, alterações musculares, problemas degenerativos, alterações funcionais, problemas emocionais e estresse ${ }^{3}$.

Dentre os sintomas estão a dor na ATM, cefaleia, estalos, otalgia, dor facial, dor cervical, cansaço, limitação de abertura de boca, dor durante a mastigação, zumbido e dor na mandíbula ${ }^{4}$, além do agravo de dores de cabeça pré-existentes, cujo desconforto e estresse podem causar tensão nos músculos da mastigação, podendo se estender aos músculos do pescoço e ombro ${ }^{5}$.

É frequente a associação de DTM e dores na cabeça e nos músculos cervicais, justificada pela relação neurofuncional e anatômica existente entre a ATM, a coluna cervical e o crânio ${ }^{2}$. Fatores como as alterações posturais da cabeça e coluna cervical e a interdependência entre o sistema sensório-motor cervical e trigeminal são apontados como possíveis causas para a $\mathrm{DCCM}^{6}$.

A relação anatomofuncional entre articulação temporomandibular, músculos inervados pelo trigêmeo e estruturas da orelha embasa a hipótese da origem dos sintomas otológicos em pacientes com DTM, como a sensação de plenitude auricular, zumbido, otalgia, vertigem, prurido na orelha externa e a sensação de perda auditiva ${ }^{7}$.

De modo individual, a anamnese é o meio mais importante para a formulação da impressão diagnóstica inicial, realizada a fim de identificar fatores predisponentes, iniciadores e perpetuantes. $\mathrm{O}$ profissional deve estar atento ao envolvimento ou não de fatores psicológicos, emocionais (ansiedade, estresse e depressão), cognitivos (expectativas e significados) e sociais, já que o substrato emocional está presente em muitos casos de DTM. O exame físico consiste na palpação da ATM e musculatura, mensuração da movimentação ativa e análise de 
ruídos articulares. Como meios auxiliares, há a polissonografia e as imagens da $\mathrm{ATM}^{8}$.

Identificar e controlar os fatores etiológicos estão diretamente relacionados ao sucesso do tratamento que, muitas vezes, envolve uma equipe multidisciplinar, associando abordagens odontológicas com outras áreas ${ }^{9}$. O tratamento conservador e não-invasivo é o preconizado inicialmente, associando procedimentos como orientações, terapias com placas oclusais, farmacoterapia e fisioterapia ${ }^{1}$.

A finalidade deste trabalho é realizar uma revisão de literatura sobre etiologia, manifestações clínicas, fisiopatogenia, diagnóstico e tratamento das disfunções craniocervicomandibulares associadas a sintomatologia vestibulococlear, a fim auxiliar acadêmicos e profissionais no estudo desta condição dolorosa crônica.

\section{REVISÃO DA LITERATURA}

\section{○ Etiologia}

A literatura apresenta a DTM como um termo comum para um conjunto de sinais e sintomas envolvendo músculos da mastigação, a ATM e estruturas associadas, sendo uma condição de etiologia complexa e multifatorial, relacionada a fatores predisponentes, desencadeantes e perpetuantes $^{2,10}$.

Grade et al. ${ }^{11}$ citam que $80 \%$ da etiologia da DTM é a hiperatividade muscular, a qual tem como principal causa os hábitos parafuncionais, agravados muitas vezes por componentes psicológicos. A ATM e a região cervical apresentam conexões musculares e ligamentares, cuja associação forma o sistema funcional craniocervicomandibular. Devido a esta relação, alterações posturais podem levar a um processo de desvantagem biomecânica da ATM e, consequentemente, a um quadro de DTM.

Cardoso et al. ${ }^{12}$ descrevem hábitos parafuncionais como um grupo de hábitos que não estão relacionados à execução de funções normais do sistema estomatognático, resultando em acúmulo de carga sobre as suas estruturas, tais como bruxismo, morder a língua e bochecha e pressionar a língua contra os dentes.

O bruxismo é apontado como uma das principais causas da DTM. Trata-se de atividade motora orofacial caracterizada por repetidas ou sustentadas contrações dos músculos elevadores da mandíbula, capazes de desenvolver rigor muscular em torno de 150 a $340 \mathrm{~kg}$ de carga puntiforme nos períodos ativos. Classifica-se em bruxismo cêntrico, (apertamento maxilo-mandibular) ou excêntrico (apertamento e deslizamento), podendo ocorrer tanto durante o dia quanto durante a noite e em períodos de não-consciência, apresentando sinais e sintomas quando o limiar de resistência dos tecidos é ultrapassado $^{12,13}$.
Cardoso et al. $^{12}$ reforçam que, apesar da capacidade de resistir e se adaptar a cargas funcionais, a ATM não é capaz de tolerar cargas compressivas por tempo prolongado, como as que ocorrem durante o apertamento, cuja pressão é maior que $200 \mathrm{mmHg}$, superiores a dos capilares periféricos, que é de $40 \mathrm{mmHg}$. Essa exacerbação gera um quadro de hipóxia local temporária, seguida de reoxigenação no período de pausa da parafunção, resultando na liberação de radicais livres, com consequente dano aos componentes celular e extracelular, estimulando a síntese de citocinas próinflamatórias.

Assim como Grade et al. ${ }^{11}$, Basso ${ }^{14}$ cita a hiperatividade dos músculos mastigatórios como correspondente à grande parte da etiologia das DTMs e a relaciona com desvios na postura corporal, os quais, por sua vez, possibilitam uma desvantagem biomecânica da ATM, comprovando a inter-relação entre o sistema estomatognático $(\mathrm{SE})$ e os músculos cervicais.

A posição anormal da cabeça altera as relações biomecânicas craniomandibulares, do mesmo modo que a posição mandibular anormal leva a alterações craniocervicais ${ }^{15}$, devido a complexas conexões neuromusculares existentes entre esses sistemas, sendo assim, a associação entre desvios posturais dos ombros, coluna cervical, cabeça e outros segmentos podem levar à disfunção craniocervical e, posteriormente, atuam como fatores perpetuadores da DTM $^{14}$.

No trabalho de Amantéa et al. ${ }^{16}$, verificou-se que a atividade aumentada da musculatura mastigatória leva a anteriorização cérvico-escapular, através da interferência nos músculos de contra-apoio - esternocleidomastoideo, trapézio - levando ao encurtamento dos músculos posteriores do pescoço e alongamento dos anteriores, acarretando em uma projeção anterior do corpo, ultrapassando o quadrilátero de sustentação. Ao mesmo tempo, a posição anterior da cabeça acarretará em distúrbios do posicionamento e funcionamento mandibular, levando a uma crescente tensão na musculatura mastigatória e, consequentemente, DTM. Já a alteração do posicionamento dos ombros se dá por elevação ou protrusão do mesmo lado da ATM afetada, uma vez que a hiperatividade dos músculos da mastigação leva a hiperatividade da musculatura cervical, contraindo os músculos elevadores e protrusores dos ombros. Assim como os ombros, a cabeça tende a apresentar alteração para o lado em que ocorre o fenômeno doloroso, ficando inclinada e/ou rodada.

Anselmo ${ }^{17}$ cita a teoria psicológica, segundo a qual os distúrbios emocionais poderiam iniciar uma hiperatividade muscular, induzida pelo sistema nervoso central e levar a ocorrência de parafunção, causando dores e, indiretamente, desarranjos oclusais. No mesmo trabalho, a autora se refere à 
teoria psicofisiológica, na qual os espasmos dos músculos mastigatórios constituem-se no fator primário para os sintomas da síndrome dor-disfunção.

Os fatores psicológicos são divididos em (1) fatores comportamentais, como o bruxismo, os quais determinam uma atitude, podendo contribuir para o estabelecimento e manutenção da dor; (2) fatores emocionais, como ansiedade, depressão e estresse, contribuindo diretamente para a perpetuação da DTM pela contração frequente dos músculos mastigatórios, provocando danos teciduais aos componentes do sistema estomatognático, criando um ciclo vicioso de dor-estresse-dor; e (3) fatores cognitivos, como expectativas e significados, os quais influenciarão a resposta do indivíduo mediante ao quadro doloroso $^{18,19}$.

\section{- Manifestações Clínicas e Fisiopatogenia}

As disfunções temporomandibulares são a causa não-odontológica mais comum de dor orofacial $^{2}$, com sinais e sintomas agrupados em DTM muscular ou DTM articular, de acordo com as estruturas afetadas, sendo os distúrbios funcionais dos músculos mastigatórios a queixa mais comum dos pacientes. Um exemplo é a denominada dor miofascial, uma dor miógena regional caracterizada por pontos-gatilho ${ }^{20}$.

Dor orofacial, ruídos articulares e restrição da função mandibular são considerados os pontos cardinais das DTMs ${ }^{4}$. A dor normalmente se localiza na área pré-auricular irradiando-se para a região temporal, frontal ou occipital. Pode apresentar-se como uma cefaleia, otalgia, zumbido na orelha ou mesmo dor de dente. Acredita-se que o espasmo dos músculos da mastigação é o principal responsável pela sintomatologia dolorosa na DTM e pode ser desencadeado por distensão, contração ou fadiga muscular $^{16}$.

É importante que o profissional conheça as vias sensitivas responsáveis pela transmissão dos estímulos até as áreas cerebrais responsáveis pela sua percepção. No aspecto da sensibilidade craniofacial, o elemento mais importante do ponto de vista anatômico é o nervo trigêmeo e, ainda, os ramos superficiais provenientes de raízes cervicais, além dos nervos cranianos facial, glossofaríngeo e vago $^{21}$.

Merril $^{22}$ cita que grande parte da literatura sobre dor fala a respeito dos mecanismos do corno dorsal quando se referem ao SNC, contudo, para a dor orofacial, a correlação trigeminal para o corno dorsal é o núcleo trigeminal no tronco encefálico. $\mathrm{Na}$ periferia, o nervo trigêmeo provê estímulos sensoriais ascendentes da porção anterior da cabeça, incluindo as estruturas intraorais. As fibras sensitivas são divididas em mecanoceptores A-beta e três tipos de fibras nociceptivas: fibras A-delta, fibras-C e fibras nociceptivas silenciosas ou dormentes, as quais podem ser amielinizadas ou superficialmente mielinizadas. Os impulsos aferentes de todas estas fibras transitam pela periferia, através do gânglio trigeminal e da raiz do trigêmeo, entrando pela ponte e descendo através do trato trigeminal para entrar no núcleo homônimo. Uma vez que as fibras tenham passado pela ponte, elas estão no SNC.

Conforme o relatado por Sydney e Conti ${ }^{23}$, os neurônios aferentes primários possuem axônios de diferentes espessuras, sendo as mais calibrosas as fibras A (alfa, beta, gama e delta) e as mais delgadas, as fibras C. As mais calibrosas conduzem os impulsos mais rápido do que as menos calibrosas. O tipo da fibra está relacionado com o tipo de impulso que ela transmite, ou seja, fibras A alfa (13-20 $\mu \mathrm{m})$, beta $(6-13 \mu \mathrm{m})$ e gama $(3-8 \mu \mathrm{m})$, que são rápidas, conduzem estímulos de propriocepção e tato. Já as fibras mais lentas, fibras A delta (1-5 $\mu \mathrm{m})$ e C (0,5-1 $\mu \mathrm{m})$ conduzem estímulos dolorosos. Há dois tipos de estímulos dolorosos: um em alfinetada, rápido, conduzido pelas fibras A delta e outro em queimação, transmitido pelas fibras $\mathrm{C}$, mais lentas.

Okeson $^{20}$ explica o mecanismo da dor referida de duas maneiras. A primeira diz que um estímulo aferente constante e prolongado bombardeia continuamente um interneurônio, resultando em um acúmulo de substância neurotransmissora na sinapse, a qual pode se espalhar para um interneurônio adjacente, fazendo com que se torne também excitado. A partir daí os impulsos irão para o cérebro, centralmente, e este percebe a nocicepção como sendo transmitida por ambos os neurônios. O neurônio excitado originalmente é que proporciona estímulos da origem verdadeira da dor (dor primária), enquanto o outro neurônio está apenas centralmente excitado. Portanto, a percepção da dor pelo cérebro a partir deste neurônio é dor heterotópica (especificamente, dor referida). A segunda explicação do efeito excitatório central é a da convergência, na qual muitos neurônios de entrada podem fazer sinapse com um único interneurônio, que pode ser, ele próprio, um dos muitos neurônios que convergem para fazer sinapse com o próximo interneurônio ascendente. Uma vez que esta convergência se aproxima do tronco encefálico e do córtex, pode ser cada vez mais difícil para o córtex avaliar a localização precisa do estímulo. Em circunstâncias normais, o córtex faz um excelente trabalho de diferenciar o local. No entanto, na presença de dor profunda contínua, a convergência pode confundir o córtex, resultando na percepção de dor em estruturas normais (dor heterotópica). As dores que causam os efeitos desse tipo de dor são constantes e têm sua origem em estruturas profundas, como as músculoesqueléticas.

Os neurônios que conduzem vários tipos de impulsos sensitivos da região da cabeça e do pescoço, em sua maioria, fazem sinapse na parte caudal do núcleo espinhal do nervo trigêmeo, para os quais convergem informações e $74 \%$ das fibras nervosas de 
sinais múltiplos podem ser ativadas por estímulos vindos de três ou mais estruturas diferentes. Esse alto índice de convergência no núcleo espinhal do nervo trigêmeo explica a dificuldade de localização da fonte da dor, especialmente da dor profunda, explicando, dessa maneira, as observações clínicas de que a dor proveniente dos músculos da mastigação pode referir para outras estruturas, incluindo o pescoço ${ }^{24}$.

A dor referida é desencadeada espontaneamente ou sob estímulo mecânico por pontos-gatilho miofasciais (PGM), que são pequenas áreas hipersensíveis localizadas em bandas musculares tensas palpáveis no músculo esquelético. São considerados ativos quando, ao serem estimulados, geram dor referida reproduzindo a queixa dolorosa preexistente do paciente. Já os latentes, localizam-se em áreas assintomáticas e só provocam dor local e referida quando estimulados, sendo menos dolorosos à palpação ${ }^{25}$. O estado ativo pode reverter-se espontaneamente para latente quando há repouso e ausência de fatores desencadeantes, assim os PGM latentes podem ser ativados por uma lesão muscular direta, por fadiga e por estresse emocional ${ }^{26}$.

Em seu trabalho, Albuquerque ${ }^{24}$ cita o aumento patológico na liberação de Acetilcolina $(\mathrm{ACH})$ pela terminação nervosa em uma placa motora anormal em repouso como a principal alteração para dar início ao fenômeno da hipótese integrada do ponto-gatilho, que se refere às informações de fontes eletrofisiológicas e histopatológicas envolvidas em seu processo de formação, criando o conceito de crise de energia. Se um ponto-gatilho excita centralmente um grupo de interneurônios convergentes, a dor irá referir geralmente em um padrão previsível e conhecer esse padrão é essencial, a fim de direcionar os procedimentos diagnósticos e terapêuticos para a origem da dor e não para o local da queixa.

Este trabalho expõe a seguir uma representação esquemática sobre o padrão de referência de músculos da mastigação e cervicais, tendo como referência a associação entre as explicações de Travell $^{27}$ e Okeson ${ }^{20}$.

\section{- Masseter (Figura 1)}

- Camada superficial

Parte superior: dentes posteriores superiores; Parte inferior: dentes posteriores inferiores; Ângulo da mandíbula: corpo da mandíbula e dor em trajeto de arco passando pelo temporal e extremidade externa da sobrencelha.

- Camada profunda

ATM e orelha.

- Temporal (Figura 2)

- Feixe anterior: acima do rebordo supra-orbital e dentes incisivos superiores; Feixe médio: prémolares, temporal e, com menos frequência, ATM;

- Feixes posteriores: molares superiores e occipital.

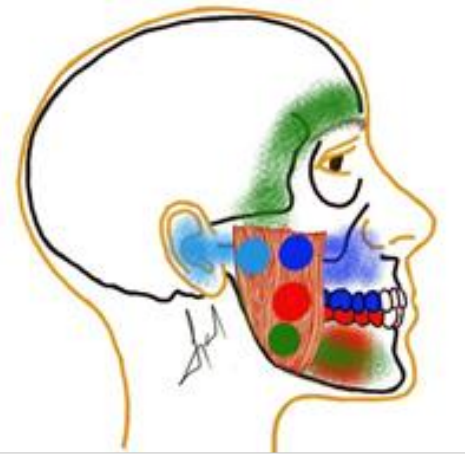

Figura 1: Padrão de dor referida do músculo masseter. Azul escuro: parte superior; vermelho: parte inferior; verde: ângulo da mandíbula; azul claro: camada profunda.

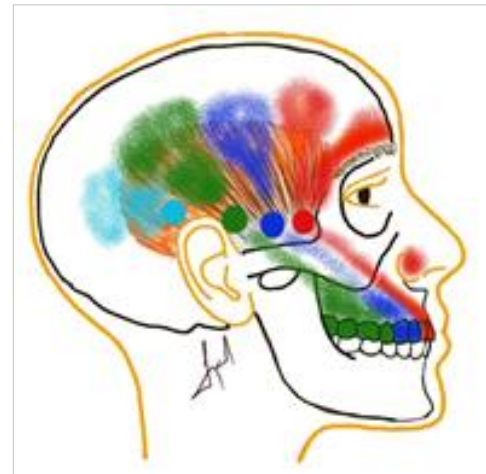

Figura 2: Padrão de dor referida do músculo temporal. Vermelho: feixe anterior; azul escuro: feixe médio; verde e azul claro: feixes posteriores.

\section{○ Pterigoideo Medial (Figura 3)}

Estruturas da boca, língua, palato duro posterior e ATM.

- Pterigoideo lateral (Figura 4)

Dor profunda dentro das regiões maxilares e temporomandibulares. Principal fonte de dor miofascial de dor referida na ATM.

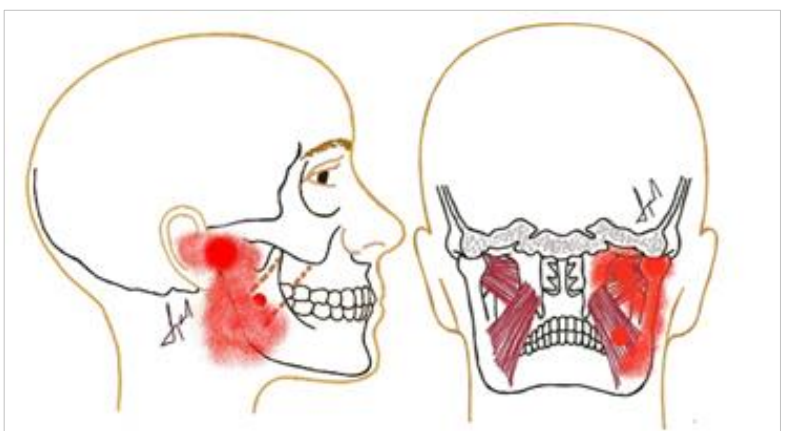

Figura 1: Padrão de dor referida do músculo pterigoideo medial.

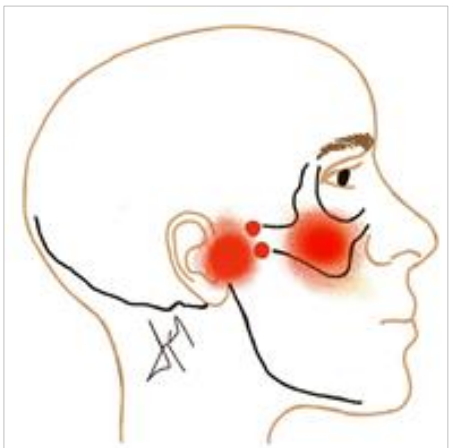

Figura 2. Padrão de dor referida do músculo pterigoideo lateral. 


\section{- Trapézio (Figura 5)}

Ângulo da mandíbula, aspecto posterolateral do pescoço, região atrás da orelha, parte posterior da órbita, molares inferiores, occipital, produz rigidez muscular no pescoço e dor de cabeça na região temporal.

\section{- Esternocleidomastoideo (Figura 6)}

Testa, rebordo supraorbital, ângulo interno do olho, orelha média e região auricular posterior, mento, faringe, dor difusa na face e raramente nos dentes molares. A divisão esternal também reproduz dor referida para baixo do esterno (sensação de aperto no peito), visão turva, lacrimação e coriza; já a divisão clavicular causa sudorese homolateral da testa, tontura postural e desequilíbrio.

- Digástrico (Figura 7)

Ventre anterior: dentes anteriores inferiores; ventre posterior: região mastoidea.

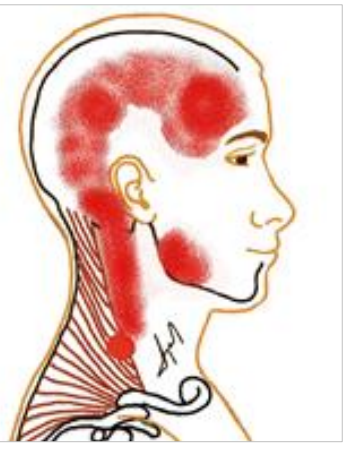

Figura 3: Padrão de referência do músculo trapézio.

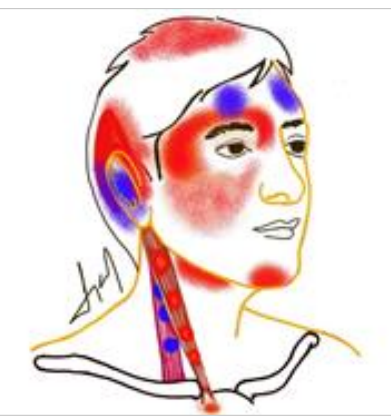

Figura 4. Padrão de dor referida do músculo esternocleidomastoideo. Azul escuro: divisão clavicular; vermelho: divisão esternal.

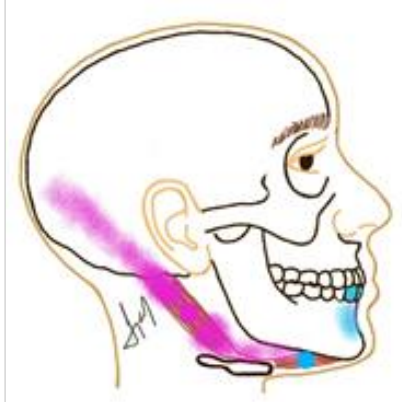

Figura 5: Padrão de dor referida do músculo digástrico. Azul claro: feixe anterior; rosa: feixe posterior.

Manfredi et al. ${ }^{28}$ explicam que o músculo esternocleidomastoideo, que possui sua inervação sensitiva proveniente do segundo e terceiro nervos cervicais, não é um músculo diretamente relacionado à mastigação, e a positividade à palpação dolorosa deve-se a impulsos nervosos do nervo trigêmeo, provenientes do tecido periodontal, lingual, das ATMs e de receptores musculares, que podem influenciar ramos de motoneurônios deste músculo. Impulsos trigeminais devem ser considerados, devido à relação existente entre tratos descendentes do nervo trigeminal e raízes cervicais altas. Neurônios das três divisões do nervo trigêmeo e dos nervos cranianos VII, IX, e X dividem os mesmos feixes neuronais com neurônios provenientes dos primeiros segmentos cervicais.

Quanto aos sintomas otológicos, Jacob et al. ${ }^{29}$ comentam que, ao avaliarem a prevalência dos sintomas otológicos nos pacientes portadores de DTM, relacionando sua presença com a dor muscular, a dor referida na orelha, plenitude auricular e tontura foram significantes na correlação da dor com a palpação positiva de PGM dos músculos masseter e esternocleidomastoideo. Concluíram também que o aumento da contração muscular desses dois músculos pode ser o responsável por sintomas otológicos na DTM. Os espasmos dos músculos mastigatórios podem se dissipar para o músculo tensor do véu palatino dificultando a sua atuação na abertura da tuba auditiva, podendo ocorrer disfunção da mesma.

Em um estudo transversal realizado em 8 pacientes de um projeto de reabilitação vestibular, foi apontado que o número de sintomas otológicos referidos é diretamente proporcional à gravidade da DTM. O aparecimento de sintomas como tontura, vertigem, alterações da marcha, náuseas, risco de queda e dificuldade de fixação dos olhos pode ser desencadeado por alterações no sistema vestibular ou por problemas clínicos à distância em outros órgãos ou sistemas. A correlação entre alterações na ATM e tais sinais e sintomas é justificada embriológica, fisiológica e anatomicamente: a mandíbula e os ossículos da orelha média têm a mesma origem embrionária, na cartilagem de Meckel, e anatomicamente a região da ATM está muito próxima ao sistema auditivo, assim como suas artérias, veias e nervos são inter-relacionados. Assim, qualquer alteração fisiológica poderá prejudicar as estruturas anatômicas adjacentes ${ }^{30}$.

\section{- Diagnóstico e Tratamento}

Chaves, Oliveira e Grossi ${ }^{31}$ caracterizaram em seu estudo os principais instrumentos de avaliação da disfunção temporomandibular disponíveis na literatura. São descritos o Questionário de Sintomas Mandibulares e Hábitos Orais, o RDC/TMD - Research Diagnostic Criteria for Temporomandibular Disorders ou Critério de Diagnóstico para Pesquisa em Disfunção Temporomandibular, e o Critério de Diagnóstico Clínico (CDC/TMD). Para os autores do estudo, quando objetiva-se obter um diagnóstico, destacam- 
se o Critério para Diagnóstico Clínico para DTM e o $\mathrm{RCD} / \mathrm{TMD}$, sendo este último uma das mais bem estruturadas ferramentas disponíveis na literatura.

Em contrapartida, Sartoretto, Bello e Bona ${ }^{8}$ consideram que ainda não há método confiável de diagnóstico e mensuração da presença e da severidade da DTM que possa ser usado de maneira irrestrita por pesquisadores e clínicos, porém, apresentam a anamnese como o passo mais importante na formulação da impressão diagnóstica inicial, com identificação de fatores causais.

A avaliação clínica deve incluir uma história médica completa, começando com a queixa principal, devendo também ser realizado exame físico do sistema mastigatório e avaliação radiográfica da ATM. A história da doença atual deve ser abrangente e conter uma descrição detalhada dos sinais e sintomas apresentados pelo paciente, bem como da sequência temporal do aparecimento destes, e como estes afetam o paciente, além dos tratamentos realizados anteriormente. Sequentemente, realiza-se exame físico, composto de uma avaliação completa do sistema mastigatório ${ }^{4}$.

A palpação é realizada digitalmente ou com o auxílio de algum aparelho (algômetro ou pressurômetro) para a identificação de dor, tonicidade muscular, pontos-gatilho e edema. $\mathrm{Na}$ palpação manual, aplica-se pressão firme com a ponta do(s) dedo(s) indicador e/ou médio, com pequenos movimentos circulares, comprimindo firmemente o músculo em condição de repouso durante um a dois segundos ${ }^{31}$.

O tratamento das DTMs objetiva controlar a dor, recuperar a função do aparelho mastigatório, reeducar o paciente e amenizar cargas adversas que perpetuam o problema, optando-se inicialmente por terapias não invasivas e reversíveis. Educação do paciente, automanejo, intervenção comportamental, uso de fármacos, placas interoclusais, treinamento postural e exercícios são opções aplicáveis a quase todos os casos. A prática da Odontologia Baseada em Evidência (OBE) não ampara técnicas que promovam mudanças oclusais complexas e irreversíveis, desde ajustes oclusais por desgastes seletivos até técnicas de reabilitação protética. Quanto às cirurgias de ATM, são necessárias em alguns poucos casos específicos, como anquilose, fraturas e determinados distúrbios congênitos ou de desenvolvimento. Excepcionalmente são aplicáveis para complementar o tratamento em transtornos internos da ATM ${ }^{1}$.

$O$ restabelecimento de uma oclusão ideal, aumento da dimensão vertical de oclusão, alteração da posição condilar para uma posição músculoesquelética mais estável e descompressão da ATM, alteração na propriocepção (diminuindo a atividade parafuncional), relaxamento muscular inicial, alteração cognitiva e efeito placebo estão entre os mecanismos de ação dos dispositivos interoclusais ${ }^{32}$.
A sua milimetragem (2 a $3 \mathrm{~mm}$ ) simula o espaço interoclusal ou espaço livre existente em condição repouso mandibular ${ }^{33^{3}}$.

No estudo de Sobreira e Zampier ${ }^{34}$ sobre a terapia farmacológica nas desordens temporomandibulares, comenta-se que o seu papel é na maioria das vezes coadjuvante, sendo mais eficiente como parte de um programa que envolva outras opções terapêuticas conservadoras. É necessário conhecer a origem, o tempo de duração e a intensidade da dor antes da seleção do fármaco. As classes consideradas nesse contexto são os analgésicos opioides e não opioides, corticosteroides, ansiolíticos, antidepressivos, relaxantes musculares e anestésicos locais.

De acordo com a American Academy of Craniomandibular Disorders e a Minnesota Dental Association, a fisioterapia tem um papel importante no tratamento das desordens temporomandibulares, objetivando o alívio da dor musculoesquelética, redução da inflamação e restauração da função motora normal. Dentre as intervenções adotadas, citam-se as modalidades de exercícios e técnicas de terapia manual. Os exercícios priorizam a musculatura mastigatória e da região cervical para a melhora da força e mobilidade da região, já a terapia manual é usada geralmente para melhora da dor e restauração da mobilidade articular ${ }^{35}$.

O acúmulo de resíduos metabólicos resultante do metabolismo anaeróbico e irrigação sanguínea insuficiente nos músculos em hiperatividade é gerador e perpetuador de espasmo e dor. Neste contexto, os efeitos da termoterapia através do calor úmido incluem vasodilatação, aumento do fluxo sanguíneo e da oxigenação, eliminação dos resíduos metabólicos, diminuição da condução nervosa da dor, diminuição da rigidez nas articulações e relaxamento muscular; as compressas frias resultam em vasoconstrição, diminuição da inflamação e da dor, miorrelaxamento de fibras profundas, redução do espasmo muscular e da rigide $^{36,37}$. O calor é indicado para casos de dor crônica com tensão muscular e crises de algia e o frio é indicado nos casos de limitações articulares póstraumáticas e pós-operatórias, relaxamento de espasmos musculares e processos dolorosos agudos ${ }^{38}$.

Outra modalidade de tratamento não invasivo com efeitos anti-inflamatório e analgésico é a laserterapia de baixa potência. Ela atua de forma a estimular a produção de $\beta$-endorfinas e o controle da produção de prostaglandinas, com diminuição da dor e redução da contração muscular, por meio da bioestimulação das fibras dos músculos envolvidos. Através de avaliação eletromiográfica (EMG) de pacientes com DTM, Shinozaki et al. ${ }^{39}$ constataram o relaxamento imediato dos músculos masseter e temporal através do uso de laserterapia. Os autores acrescentam que, apesar de a severidade da dor não 
ser refletida nas atividades EMG, a tonicidade muscular aumentada dos pacientes disfuncionais é detectada através da eletromiografia, tornando-a, deste modo, uma eficiente modalidade avaliativa e diagnóstica das DTMs.

List e Jensen $^{40}$ citam ainda as terapias comportamentais como eficazes no tratamento de DTM, as quais incluem aconselhamento, educação, biofeedback, terapia cognitivo-comportamental, inversão de hábitos e autotratamento em casa após a instrução e técnicas de relaxamento. A necessidade de tratamento para DTM na população adulta em geral é substancial e varia de acordo com a definição, critérios e idade, não existindo uma abordagem única para o tratamento.

\section{CONCLUSÃO}

Alterações na musculatura mastigatória podem atuar de forma bidirecional com as alterações na musculatura cervical, justificando-se pelas relações anatômicas e neurofuncionais de ambas. A atividade aumentada de músculos dessas regiões, tais como do masseter e esternocleidomastoideo, pode desencadear sintomas referidos no sistema auditivo, manifestados principalmente como plenitude auricular, zumbido e otalgia. Tendo em vista a complexidade dessas relações e o caráter multifatorial da disfunção craniocervicomandibular, é indispensável que o profissional saiba identificar a etiologia da dor e, a partir de então, lançar mão de uma combinação de abordagens terapêuticas, sendo esta mais eficaz do que terapias isoladas.

\section{REFERÊNCIAS}

1. Carrara SV, Conti PCR, Barbosa JS. Termo do $1^{\circ}$ consenso em disfunção temporomandibular e dor orofacial. Dental Press J Orthod. 2010;15(3):114-20.

2. Pozzebon D. Dor e disfunção craniocervicomandibular, ansiedade e depressão em profissionais da Enfermagem sob estresse no trabalho [dissertação]. Santa Maria: Universidade Federal de Santa Maria; 2015.

3. Barreto DC, Barbosa AR, Frizzo AC. Relação entre disfunção temporomandibular e alterações auditivas. Rev. CEFAC. 2010;12(6):1067-76.

4. Santos PP, Santos PR, Souza LB. Características gerais da disfunção temporomandibular: conceitos atuais. Rev Naval Odontol. 2009;3(1):10-3.

5. Bove SRK, Guimarães AS, Smith RL. Caracterização dos pacientes de um ambulatório de disfunção temporomandibular e dor orofacial. Rev Latino-am Enfermagem. 2005;13(5):686-91.

6. Weber P, Corrêa ECR, Ferreira FS, Soares JC, Bolzan GP, Silva AM. Frequência de sinais e sintomas de disfunção cervical em indivíduos com disfunção temporomandibular. J Soc Bras Fonoaudiol. 2012;24(2):134-39.
7. Felício CM, Faria TG, Silva MA, Aquino AM, Junqueira CA. Desordem Temporomandibular: relação entre sintomas otológicos e orofaciais. Rev Bras Otorrinolaringol. 2004;70(6):786-93.

8. Sartoretto SC, Bello YD, Bona AD. Evidências científicas para o diagnóstico e tratamento da DTM e a relação com a oclusão e a ortodontia. RFO. 2012; 17(3):352-59.

9. Maydana AV, Tesch RS, Denardin OVP, Ursi WJ, Dworkin SF. Possíveis fatores etiológicos para desordens temporomandibulares de origem articular com implicações para diagnóstico e tratamento. Dental Press J Orthod. 2010;15(3):7886.

10.Santos PP, Santos PR, Souza LB. Características gerais da disfunção temporomandibular: conceitos atuais. Rev Nav Odontol. 2009;3(1):10-3.

11. Grade R, Caramês J, Pragosa A, Carvalhão J, Sousa S. Postura e disfunção temporo-mandibular: controvérsias actuais. Rev port estomatol cir maxilofac. 2008;49(2):111-17.

12.Cardoso LM, Kraychete DC, de Araújo RP. A relevância do apertamento dentário nas desordens temporomandibulares. R C med biol. 2011; 10(3):277-83.

13. Molina OF, Gaio DC, Cury MDN, Cury SE, Gimenez SRM, Salomão EC, Pinesci E. Uma análise crítica dos sistemas de classificação sobre o bruxismo: implicações com o diagnóstico, severidade e tratamento dos sinais e sintomas de DTM associados com o hábito. JBA. 2002;2(5):61-39.

14.Basso DBA. Atividade muscular, alinhamento corporal e avaliação clínica de indivíduos com disfunções temporomandibulares e com desvios posturais antes e após reeducação postural global (RPG) [dissertação]. Santa Maria: Universidade Federal de Santa Maria; 2009.

15.Ritzel CH, Diefenthaeler F, Karolczak AP, Rodrigues AM, Guimarães AC, Vaz MA. A relação entre a musculatura mastigatória e cervical na disfunção craniocervicomandibular. Conference Paper. 2005.

16. Amantéa DV, Novaes AP, Campolongo GD, Barros TP. A importância da avaliação postural no paciente com disfunção da articulação temporomandibular. Acta Ortop Bras. 2004;12(3):155-59.

17.Anselmo SM. Fatores psicológicos relacionados às desordens temporomandibulares: avaliação de pacientes submetidos a tratamento com aparelhos oclusais planos e reabilitação oral. [Tese]. Piracicaba: Universidade Estadual de Campinas; 2005.

18.Cestari K, Camparis CM. Fatores psicológicos: sua importância no diagnóstico das desordens temporomandibulares. JBA. 2002;2(5):54-60. 
19.Ferreira KD, Guimarães JP, Batista CH, FerrazJúnior AM, Ferreira LA. Fatores psicológicos relacionados à sintomatologia crônica das desordens temporomandibulares - revisão de literatura. RFO. 2009;14(3):262-67.

20.Okeson JP. Tratamento das Desordens Temporomandibulares. 7.ed. Rio de Janeiro: Elsevier; 2013.

21.Rabello GD. Dores orofaciais. In: Manganello LC, Silveira ME, Silva AA. Cirurgia da articulação temporomandibular. São Paulo: Gen; 2014.

22. Merril RL. Mecanismos da dor orofacial e suas aplicações clínicas. JBA. 2001;1(4):335-49.

23. Sydney PB, Conti PC. Diretrizes para avaliação somatossensorial em pacientes portadores de disfunção temporomandibular e dor referida orofacial. Rev Dor. 2011;12(4):349-53.

24. Albuquerque JP. Pontos-gatilho dos músculos da cabeça e pescoço e suas áreas de referência [dissertação]. Campinas: Centro de PósGraduação São Leopoldo Mandic; 2008.

25.Rocha CA, Sanchez TG, Siqueira JT. Pontosgatilho miofasciais: ocorrênciaa e capacidade de modulação em pacientes com zumbido. Arq. Int. Otorrinolaringol. 2006;10(3):210-17.

26. Bigongiari A, Franciulli PM, Souza FA, Mochizuki L, Araújo RC. Análise da atividade eletromiográfica de superfície de pontos gatilhos miofasciais. Rev Bras Reumatol. 2008;48(6):31924.

27. Travell J. Temporomandibular joint pain referred from muscles of the head and neck. J Pros Den. 1960;10(4):745-63.

28. Manfredi AP, da Silva AA, Vendite LL. Avaliação da sensibilidade do questionário de triagem para dor orofacial e desordens temporomandibulares recomendado pela Academia Americana de Dor Orofacial. Rev Bras Otorrinolaringol. 2001; 67(6):763-68.

29.Jacob LC, Rabiço TM, Campêlo RM, Aguiar FP, Zeigelboim BS. Sintomas auditivos e análise das emissões otoacústicas evocadas por estímulo transiente em indivíduos portadores de disfunção temporomandibular. Distúrb Comum. 2005;17(2):173-82.

30.Farias KR. Sinais e sintomas de desordens temporomandibulares em pacientes portadores de disfunção vestibular [monografia]. Campina Grande: Universidade Estadual da Paraíba; 2015.

31. Silva RS, Conti PCR, Araújo CRP, Rubo JH, Santos CN. Palpação muscular: sensibilidade e especificidade. Jornal Brasileiro de Oclusão, ATM e Dor Orofacial. 2003; 3(10):164-69.

32. Melo GM. Mecanismo de ação dos dispositivos interoclusais. Rev Sul-Bras Odontol. 2010 jun; 7(2):216-25.
33.Cordoni RR. Ação da placa miorrelaxante como redutor de estresse bucal e dor orofacial em trabalhadores [dissertação]. Florianópolis: Universidade Federal de Santa Catarina; 2002.

34. Sobreira CR, Zampier MR. Terapia farmacológica nas desordens temporomandibulares. $\mathrm{R}$ Un Alfenas. 1999;5:239-45.

35. Oliveira KB, Pinheiro IC, Freitas DG, Gualberto HD, Carvalho NA. A abordagem fisioterapêutica na disfunção da articulação temporomandibular: revisão de literatura. Med Reabil. 2010;29(3):614.

36.Furlan RM. O uso da crioterapia no tratamento das disfunções temporomandibulares. CEFAC. 2015; 17(2):648-55.

37.Furlan RM, Giovanardi RS, Britto AT, Britto DB. O emprego do calor superficial para tratamento das disfunções temporomandibulares: uma revisão integrativa. CoDAS. 2015;27(2):207-12.

38.Favero EK. Disfunções da articulação temporomandibular: uma visão etiológica e terapêutica multidisciplinar [monografia]. São Paulo: Centro de Especialização em Fonoaudiologia Clínica; 1999.

39. Shinozaki EB, Paiva G, Zanin FA, Brugnera Júnior A. Avaliação eletromiográfica de pacientes com DTM após laserterapia. RGO. 2006;54(4):334-39.

40.List T, Jensen RH. Temporomandibular disorders: old ideas and new concepts. 2017;37(7):692-704.

\section{CONFLITO DE INTERESSES}

Os autores declaram não haver conflitos de interesse.

\section{AUTOR PARA CORRESPONDENCIA}

\section{Géssica Vasconcelos Godinho}

gessicavasconcelos22@gmail.com

Submetido em 18/09/2018

Aceito em 12/03/2019 